\title{
The Effect of Augmented Reality Applications on Customer's Purchase Intentions
}

\author{
Maram Ehab $^{1}$, Riham Adel ${ }^{2}$ and Hisham Abdelmoaty ${ }^{3}$ \\ ${ }^{1,2,3}$ College of Management \& Technology, Arab Academy for Science, Technology and Maritime Transport, \\ Alexandria, P.O. Box: 1029, Egypt
}

\begin{abstract}
An increasing number of businesses have started adopting Augmented Reality technologies. Previous research has identified that Augmented Reality can affect consumer's behaviors and responses. However, little is known about How Augmented Reality impacts the decision-making process of the customers and their purchase intention especially in the retail sector. The purpose of this study is to examine the impact of using Augmented Reality in increasing purchase intentions. An empirical study using mixed-methods combining qualitative and quantitative approaches was conducted. Results indicate that high levels of engagement can positively affect users' experience with Augmented Reality applications. Also, Results show that both dimensions "engagement" and "experience" impact users' purchase intentions.
\end{abstract}

Keywords: Augmented Reality, User Experience, Interactivity, Engagement, Purchase Intention,

\section{Introduction}

New technologies provide people with the opportunity to establish environments enriched with digital technologies to complement the possibilities that the physical world can offer (Pantano, et al., 2017).

Retailers have to respond quickly to such technological changes to be able to survive in today's highly competitive market (Huang and Liao, 2014). As a result, interactive technologies such as Artificial Intelligence (AI), Virtual Reality (VR), and Augmented Reality (AR) have grabbed the attention consumers as well as retailers.

$\mathrm{AR}$ is considered as one of the new technologies that is used in retail environment. Olsson et al. (2011) defined AR as a tool that "combines real and computer-generated digital information into the user's view of the physical real world in such a way that they appear as one environment". It is argued that AR is able to transform the shopping experience (Bonetti and Quinn, 2017, Watson et al., 2018). In addition, $\mathrm{AR}$ is one of the promising technologies that are expected to create a new concept of retail stores, where traditional and digital stores cooperate. Retailing is considered one of the sectors that have the greatest opportunities to implement AR (Caboni and Hagberg, 2019).

The majority of previous researches done on AR are limited to Technology Acceptance Model (TAM) disregarding how augmentation can provide a compelling user experience and how it can affect purchase intention. So far, limited research has been done to understand the various aspects of users' experience and its influence on consumer purchase decision-making, such insights are of high importance to retailers when considering investing in AR. Consequently, the rapid growth and the expected increasing value of AR urge the need for a proper clarification of the effect of AR on user's experience and how it related to the customer's purchase intention.

This study will be conducted specifically in Egypt as most of the previous research was carried out in developed countries with little attention to the effect of $\mathrm{AR}$ in developing countries.

\section{Review of Literature}

Companies are operating in a highly competitive environments where competitors are only one click away therefore, they are forced to provide their customers with different experiences that go beyond just offering low prices (Bilgihan et al. 2016).

To facilitate decision making and to increase interest towards the product a lot of organizations adopted service augmentation (Hilken et al., 2017).

$\mathrm{AR}$ is an interactive technology installed on smart devices and has recently gained a wide adoption by retailers (Perannagari and Chakrabarti, 2019), where products are taken directly into the living environment of users to allow them to experience those goods and feel the level to which such product can affect their lives (Huang and Hsu Liu, 2014). Kim et al. (2014) stated that AR applications have been applied into various fields including education, entertainment, medical and the robotics field. 
However, Pantano, et. al., (2017) claim that the benefits of $A R$ in the retail sector are still under examination.

\subsection{The Benefits of Using Augmented Reality for Retailers and Customers}

AR has a number of potential benefits for retailers. First of all, AR can enhance conversion and return rates as AR makes it easier to visualize the product leading to lower returned items and therefore lower cost of transporting the goods back to the store (Watson et al., 2018). In addition, AR applications can also help create stronger connections between the consumer and the products, before actually purchasing them which will help retailers increase customer's brand attachment (Dacko, 2016). AR apps are created to enable a more personalized shopping experience (Watson et al. 2018) which satisfy the higher customer demand towards products and services that are customized to their specific needs (Tabusca, 2014).

Some of the previously mentioned advantages of AR for retailers simultaneously benefit customers as well. Improving conversion rates and reducing return rates is at the same time helping customers purchase products with more certainty (Dacko, 2016). Especially that some customers fear to make an online purchase as the process is risky (Poushneh and Vasquez-Parraga, 2017).

\subsection{The Hedonic and Cognitive Factors of Users' Experience}

Cehovin, F. and Ruban, B. (2017) stated that studies on AR user experiences show that both hedonic and cognitive drivers affect the shopping experience. Hedonic features are intended to provide the user with the enjoyable experience through digital communication that may include all elements that cause pleasure, such as graphics, animation, color and other elements of design. (Papagiannidis et al., 2013; Rese et al., 2017; Papagiannidis et al., 2017). Particularly, hedonic elements play a huge role in using AR as they direct the attention to what is perceived as interesting, trigger decisions and initiate behavior. Hence, the feelings caused by the AR application will have a great effect on the user experience (Cehovin, F. and Ruban, B., 2017). In contrast, the cognitive shopping value is more directed towards task and rational (Blázquez, 2014). In the cognitive dimension, consumers focus on buying a product in a timely and efficient way to achieve their objectives with minimum errors (Childers et al. 2001). AR improves the offered cognitive value as it provides enhanced possibilities for engaging users in better product examination leading to an effective online shopping. Such "smart" technologies enable customers to engage in more productive outcomes leading to an enhanced
ISSN 2455-6378

user experience and decision making (Hilken et al. 2017).

\subsection{Engagement and User Experience}

In addition, the use of $\mathrm{AR}$ is altering the way consumers are connected in the shopping process and improving their shopping experience through higher levels of engagement in terms of higher offered values and interactivity which results in increased consumer's purchase intention (Caboni and Hagberg, 2019). AR gives consumers the opportunity to select or manipulate the content they view, or more specifically interact with, which enhances engagement resulting in a more compelling customer experience (Scholz and Smith 2016). Watson et al. (2018) argued that interactivity is a key feature of $A R$ applications. Perceived interactivity is referred to as "the degree to which user perceives that the interaction or communication is two-way, controllable, and responsive to their actions", (Mollen and Wilson, 2010).

Additionally, perceived value is considered an important factor in consumer's purchase decision process as consumers tend to purchase products offering high perceived value (Chi H. et al., 2011). Perceived value can be defined as the customer's evaluation of the benefits relative to the costs when shopping (Bonsón Ponte et al. 2015).

\subsection{Purchase Intentions}

Poushneh and Vasquez-Parraga, (2017) affirm that AR boosts the user's experience by exposing the users to more product information, than products with no augmentation. This leads to a higher user experience at time of the purchase, leading to a lower level of anxiety, and makes the decision-making easier. Purchase intention refers to the collective willingness of the participants to purchase the offered good (Papagiannidis et al., 2017).

The literature indicates that users who are interacting and engaged through AR tend to have higher intentions to purchase and they keep returning (Bilgihan et al. 2016).

It is also argued that a user's intention to purchase is influenced by an AR-enriched user experience. Additionally, previous research highlights that an exciting, novel, and engaging shopping experience has the ability to positively influence the buying behavior of customers, as consumers are more ready to dedicate more of their attention and time when engaged in the experience (Domina et al. 2012)

\section{Research Methods}

\subsection{Research Design \& Methods}

The complexity of the interaction of different attributes that contribute in the creation of a user's experience along with the novelty of AR gave 
direction to the research. Mixed methods research will be used, which combines the use of quantitative and qualitative data collection techniques with analytical procedures thus, combines the purpose of being exploratory and descriptive (Saunders et al., 2015).

The research will start as being exploratory to gain better and deeper understanding of the effect of AR in the Egyptian retail sector using a qualitative strategy, which indicates an inductive approach. Due to Covid-19 pandemic the research strategy to collect quantitative data was through designing and openended questions section in the survey instead of conducting semi-structured interviews that may require physical interaction with the participants. In addition, sequential mixed methods research is used. In this, the researchers use the above-mentioned methods in order to expand or elaborate on the initial set of findings (Saunders et al., 2015).

A descriptive study was conducted to provide a more detailed explanation of user's perceptions, which motivated the use of quantitative strategy as well. The lack of research on the effect of AR on different dimensions of a user's experience as well as its effect on purchase intention led the researcher to combine scales from different authors to create one survey that measures the intended variables. However, the researcher modified the statements of the scale to suit the context of the study. The researcher first conducted a pilot test to ensure validity and reliability of the chosen Framework. The sections of the survey relating to the variables of our conceptual framework are measured using Likert Scale, where respondents have statements where they should choose between alternatives ranging from $5=$ strongly disagree to $1=$ strongly agree. Moving to the time horizon of the research, it is a cross sectional research as it involves the study of a particular phenomenon at a particular time (Saunders et al., 2015).

\subsection{Conceptual Framework}

This research will consider engagement and customer experience with $\mathrm{AR}$ as the two main independent variables that affect the dependent variable purchase intentions. The use of $A R$ is changing the way consumers are involved in the shopping process and enhancing their shopping experience through higher engagement including perceived value and perceived interactivity which results in higher consumer's intention to purchase (Caboni and Hagberg, 2019). In addition, it is also argued that AR increases the benefits offered to customers who satisfies their need for higher perceived value. Consequently, customers enjoy their
ISSN 2455-6378

shopping experience which leads to an increased purchase intention (Dieck T., Jung T., 2017).

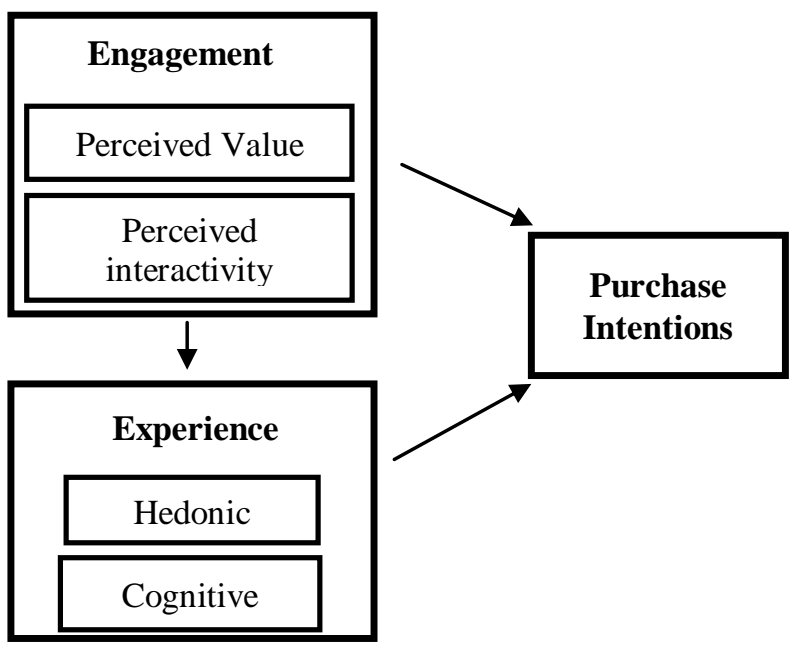

\section{H1 - Engagement has a significant effect on user experience}

H1a: perceived value has a significant impact on experience

$\mathrm{H} 1 \mathrm{~b}$ : perceived interactivity has a significant impact on experience

\section{H2 - Engagement has a significant effect on purchase intention}

$\mathrm{H} 2 \mathrm{a}$ : perceived value has a significant impact on purchase intention

$\mathrm{H} 2 \mathrm{~b}$ : perceived interactivity has a significant impact on purchase intention

\section{H3 - User experience has a significant effect on purchase intention}

H3a: hedonic dimension has a significant effect on purchase intention

$\mathrm{H} 3 \mathrm{~b}$ : cognitive dimension has a significant effect on purchase intention

\subsection{Population and Sampling}

Due to the limited applications of AR available in Egypt, which was considered one of the main difficulties that encountered the researcher during the data collection phase. Moreover, the COVID-19 crisis worldwide and the lockdown restricted the researcher ability to cover multiple retailers and access data from different sources. Therefore, the researcher narrowed its targeted population to IKEA Company especially that the researcher managed to have a contact with the management stores of IKEA in Egypt which accepted to distribute the survey online to its IKEA family customers which consist of 15.000 from the most loyal IKEA customers.

This research applies probability sampling technique as it is often associated with survey research strategy where you need to make inferences from your sample about a population to answer your research 
questions and to meet your objectives (Saunders et al., 2015).

The sample size was calculated as $5 \%$ of the target population making it 400 individuals. This sample size was calculated in accordance to Krejcie and Morgan (1970) sampling table. Consequently, random sampling technique was used. In the context of the study, online link was sent to the emails of 1000 randomly chosen customers from IKEA family database. Although the researcher's sample according to Krejcie and Morgan (1970) was 400 the researcher had a returning complete response of 563 .

\section{Results and Discussion}

This section discusses the results of the statistical analysis undergone on this study. First, a sample description will take place to calculate the probability of occurrence followed by the qualitative data analysis to gain deeper understanding of customers perceptions of AR. Afterwards, the quantitative analysis is undertaken by conducting a reliability and validity test as well as regression and correlation analysis to test the hypothesis of the study variables.

Table 1: Results of the AVE and the Factor loadings

\begin{tabular}{|c|c|c|}
\hline The study variables & $\begin{array}{l}\text { \% of variance } \\
\text { (AVE) value }\end{array}$ & $\begin{array}{l}\text { Factor loading of } \\
\text { items }\end{array}$ \\
\hline \multicolumn{2}{|l|}{ Perceived Value } & \\
\hline 1- PV1: providing easy and clear virtual experience & & 0.684 \\
\hline $\begin{array}{l}\text { 2- PV2: easy find of what I'm looking for and successful } \\
\text { completion of purchase }\end{array}$ & & 0.758 \\
\hline 3- PV3: the time I spent shopping is fun and entertaining & & 0.722 \\
\hline 4- PV4: providing supportive virtual experience & & 0.799 \\
\hline $\begin{array}{l}\text { 5- PV5: The shopping process is stimulating an makes me } \\
\text { feel good }\end{array}$ & & 0.763 \\
\hline $\begin{array}{l}\text { 6- PV6: I would recommend using it to my friends as a } \\
\text { decision aid to buy products }\end{array}$ & & 0.809 \\
\hline $\begin{array}{l}\text { 7- PV7: providing effective and efficient virtual } \\
\text { experience }\end{array}$ & & 0.803 \\
\hline \multicolumn{3}{|l|}{ Perceived Interactivity } \\
\hline $\begin{array}{l}\text { 1- Pint1: interaction with the application allows getting } \\
\text { tailored products information }\end{array}$ & \multirow{4}{*}{83.599} & 0.907 \\
\hline 2- Pint2: It is reliable, accessible and responsive & & 0.915 \\
\hline $\begin{array}{l}\text { 3- Pint3: The amount of interaction with the application is } \\
\text { sufficient and allows me to buy what I want and to do } \\
\text { shopping the way I want }\end{array}$ & & 0.908 \\
\hline $\begin{array}{l}\text { 4- Pint } 4 \text { : the interaction with the application helps to come } \\
\text { to a purchase decision of the products }\end{array}$ & & 0.927 \\
\hline \multicolumn{3}{|l|}{ Hedonic Dimension } \\
\hline 1- Em1: It makes the shopping process feel like an escape & \multirow{4}{*}{80.979} & 0.784 \\
\hline $\begin{array}{l}\text { 2- Em2: It makes me feel a It makes me feel a sense of } \\
\text { adventure and gives me excitementsense of adventure and } \\
\text { gives me excitement }\end{array}$ & & 0.82 \\
\hline $\begin{array}{l}\text { 3- Em3: It is exciting and the content incites my curiosity } \\
\text { that time just slips away }\end{array}$ & & 0.85 \\
\hline $\begin{array}{l}\text { 4- Em4: It provides an interesting and exciting virtual } \\
\text { experience }\end{array}$ & & 0.785 \\
\hline Cognitive Dimension & \multirow{4}{*}{78.802} & 0.795 \\
\hline 1- CO1: My shopping process is successful and rewarding & & \\
\hline 2- $\mathrm{CO} 2$ : ease of becoming skillful at using the application & & 0.801 \\
\hline $\begin{array}{l}\text { 3- CO3: Plan purchasing throughout AR application even } \\
\text { when same items are available at the store }\end{array}$ & & 0.768 \\
\hline
\end{tabular}


The results of this study showed that respondents were mostly from age 20-29 with a percentage of $37.4 \%$. In addition, $34.5 \%$ of the respondents were aged 30-39, given these results, the sample indicates that more than $70 \%$ of the sample of the questionnaire were within the age group of generation $\mathrm{Y}$ that was identified for the sampling of this study (Kasasa, 2020). More than half of the sample were females 56\%. Also $98.9 \%$ of the respondents were Egyptians.

\subsection{Quantitative Data Analysis}

This section of the study covers the analysis of the structured questions of the survey.

\subsubsection{Measuring Validity of Scale}

The validity test refers to the appropriateness of the measures used and the accuracy of the analysis of the results and generalizability of the findings (Saunders et al., 2015).

Convergent validity was essential to make sure that the items used within the same construct are highly correlated (O’Leary-Kelly et al., 1998). Consequently, to test the convergent validity, the average value extracted for each of the scales was calculated. The average variance (AVE) represents the average community for each latent variable, and in an adequate model it should be greater than 0.5 , which means that the factors should explain at least half the variance of their respective indicators (Hair J., et al., 2012).

Table 2: Factor Cross Loading Matrix
Based on factor analysis, the two independent variables engagement and experience have a percentage of variance value above $50 \%$.

The sub-dimensions respectively have AVE value for perceived value $=76.26 \%$, perceived interactivity $=83.59 \%$, hedonic dimension $=80.97 \%$, and finally, cognitive dimension $=78.8 \%$. In conclusion, the results of the factor analysis conducted indicate that AVE values reported for all scales were found to have convergent validity AVE values above 0.5 as represented in Table 1.

The discriminant validity however is used to ensure that the scales used measures the variables of the study are not correlated with each. Based on the study of Fornell, (2017) in order to achieve discriminant validity, the squared inter-correlation between two constructs should not exceed the AVE estimates (see Table1) of the respective two constructs for all pairs of constructs. Thus, in the current study, all measurements were found to be within the discriminant validity as the square correlation between the latent variables were found to be smaller than the AVE values from respective constructs for all of the latent variables. Table 2 summarizes the correlation coefficients between the latent variables. By squaring these variables and comparing their results with table 1 discriminant validity will be proved.

\begin{tabular}{|l|c|c|c|c|}
\hline & Perceived Value & $\begin{array}{c}\text { Perceived } \\
\text { Interactivity }\end{array}$ & $\begin{array}{c}\text { Hedonic } \\
\text { Dimension }\end{array}$ & $\begin{array}{c}\text { Cognitive } \\
\text { Dimension }\end{array}$ \\
\hline Perceived value & & & & \\
\hline Perceived Interactivity & $.602^{* *}$ & & & \\
\hline Hedonic Dimension & $.563^{* *}$ & $.563 * *$ & & \\
\hline Cognitive dimension & $.578^{* *}$ & $.619^{* *}$ & $.731^{* *}$ & \\
\hline
\end{tabular}

\subsubsection{Measuring Reliability}

This stage of the analysis is used to indicate and confirm the consistency and the degree of errors of the items in each technique that measured the variables, as well as test the harmony of the scale items all together..

Table 3: Reliability Analysis

\begin{tabular}{|c|l|l|}
\hline Variable & Number of items & Cronbach's Alpha \\
\hline Engagement $\quad 11$ & 0.958 \\
\hline Experience Perceived Value & 7 & 0.948 \\
\hline$\quad$ Perceived interactivity & 4 & 0.934 \\
\hline P Hedonic Dimension & 7 & 0.941 \\
\hline Purchase Intention & 4 & 0.920 \\
\hline Overall reliability & 3 & 0.862 \\
\hline
\end{tabular}


Cronbach Alpha is the measure used to assess the reliability whereas, the acceptable range is between 0.70 and 0.90 (Saunders et al., 2015). Consequently. In this study, the Cronbach's Alpha of the scales used in the questionnaire ranges from 0.862 up to 0.948 and no item if deleted will further increase reliability. Table 3 summarizes the reliability analysis

\subsubsection{Correlation Analysis}

Table 4: The correlation between purchase intention and studied variables

\begin{tabular}{l|c|c}
\hline \multicolumn{1}{c|}{ variables } & r Pearson & Significant \\
\hline Perceived value & .726 & 0.000 \\
\hline Perceived interactivity & .734 & 0.000 \\
\hline Hedonic dimension & .720 & 0.000 \\
\hline Cognitive dimension & .783 & 0.000 \\
\hline
\end{tabular}

Table 5: The correlation between the sub variables of engagement and hedonic dimension of experience

\begin{tabular}{l|c|c}
\hline \multicolumn{1}{c|}{ variables } & r Pearson & Significant \\
\hline Perceived value and & .750 & 0.000 \\
\hline Perceived interactivity & .720 & 0.000 \\
\hline
\end{tabular}

Table 6: The correlation between the sub variables of engagement and cognitive dimension of experience

\begin{tabular}{l|c|c}
\hline \multicolumn{1}{c|}{ variables } & r Pearson & Significant \\
\hline Perceived value & .760 & 0.000 \\
\hline Perceived interactivity & .783 & 0.000 \\
\hline
\end{tabular}

The $r$ Pearson was applied to investigate the relation between purchase intention and studied variables the results showed at table 4 prove that there is a positive, strong and significant relationship between perceived value and purchase intention whereas $r$ value was 0.726 and significant at (0.01)

There is a positive, strong and significant relationship between Perceived interactivity and purchase intention whereas $r$ value was 0.734 and significant at (0.01)

There is a positive, strong and significant relationship between hedonic dimension of experience and purchase intention whereas $r$ value was 0.720 and significant at $(0.01)$

There is a positive, strong and significant relationship between cognitive dimension of experience and purchase intention whereas $r$ value was 0.783 and significant at $(0.01)$
ISSN 2455-6378

Tables 5 and 6 show the relationship between the sub variables of engagement which are perceived value and Perceived interactivity and their relationship with the hedonic and cognitive dimension of experience. The $\mathrm{r}$ person correlation of both sub variables indicates a positive and significant relationship.

4.1.4 Regression Analysis and Hypothesis testing

The researcher used the stepwise multiple regression to explain each variables contribution through the beta coefficient. The value with the largest beta value had the strongest, significant effect. The study used the stepwise multiple regressions to also evaluate the model significance as a whole as well as the significance of each construct. In the current analysis, the $\mathrm{R}$ Squared value (Coefficient of determination) identifies the variance on the dependent variable.

Table 7: The Stepwise Multiple Regression results

\begin{tabular}{l|c|c|c}
\hline \multicolumn{1}{c|}{ Predictors } & $\begin{array}{c}\text { Beta } \\
\text { value }\end{array}$ & $\mathrm{t}$ value & Significant \\
\hline Experience & .430 & 9.577 & 0.000 \\
\hline Engagement & .413 & 9.194 & 0.000 \\
\hline F Value $=519.403^{* *}$ \\
\hline R Square $=.650$ \\
\hline
\end{tabular}

The Multiple Regression was applied to explain the variance of dependent variable (purchase intention) by studied independent variables (experience and engagement), as stated in table 7 the $F$ value was 519.403 and significant at (0.00), consequently the $r$ square value was .650 means that the studied independent variables explain about $65 \%$ for the variance of dependent variable (purchase intention).

\section{H1: Engagement has a significant effect on user experience}

H1a: perceived value has a significant effect on user experience

$\mathrm{H} 1 \mathrm{~b}$ : Perceived interactivity has a significant effect on user experience

Table 8: The Stepwise Multiple Regression results

\begin{tabular}{l|c|c|c}
\hline \multicolumn{1}{c|}{ Predictors } & $\begin{array}{c}\text { Beta } \\
\text { value }\end{array}$ & t value & Significant \\
\hline Perceived value & .418 & 11.348 & 0.000 \\
\hline $\begin{array}{l}\text { Perceived } \\
\text { interactivity }\end{array}$ & .469 & 12.733 & 0.000 \\
\hline \multicolumn{2}{l}{ F Value $=648.146^{* *}$} & & \\
R Square $=.699$
\end{tabular}


According to tables 8 the Beta value of perceived value was .418 and $\mathrm{t}$ value (11.348) and its significant at (0.00). Moving to the Perceived interactivity, the Beta value of Perceived interactivity was .469 and $t$ value (12.733) and its significant at (0.00). The $\mathrm{F}$ value was 648.146 and significant at (0.00), consequently the $r$ square value was .699 meaning that the studied sub variables of engagement explain about $69.9 \%$ for the variance experience.

In conclusion, perceived value and perceived interactivity were found to have a significant positive relationship with user experience, which was supported by Dieck T., Jung T. (2017) who argued that AR allows interactivity and higher perceived value which is crucial to providing higher levels of engagement and a more exciting user's experience. Consequently, the results support the hypothesis. Thus, H1 is accepted.

\section{H2: Engagement has a significant effect on purchase intention}

$\mathrm{H} 2 \mathrm{a}$ : perceived value has a significant impact on purchase intention

$\mathrm{H} 2 \mathrm{~b}$ : Perceived interactivity has a significant impact on purchase intention

Table 9: The Stepwise Multiple Regression results

\begin{tabular}{l|c|c|c}
\hline \multicolumn{1}{c|}{ Predictors } & Beta value & $\mathrm{t}$ value & Significant \\
\hline $\begin{array}{l}\text { Perceived } \\
\text { value }\end{array}$ & .392 & 9.237 & 0.000 \\
\hline $\begin{array}{l}\text { Perceived } \\
\text { interactivity }\end{array}$ & .430 & 10.134 & 0.000 \\
\hline \begin{tabular}{l} 
F Value $=419.350^{* *}$ \\
\hline R Square $=.600$
\end{tabular} \\
\hline
\end{tabular}

In addition, table 9 shows that the Beta value of perceived value was .392 and t value (9.237) and its significant at (0.00). Moving to the Perceived interactivity, the Beta value of Perceived interactivity was .430 and t value (10.134) and its significant at (0.00). The $\mathrm{F}$ value was 419.350 and significant at (0.00), consequently the $r$ square value was .600 meaning that the studied sub variables of engagement explain about $60 \%$ for the variance of dependent variable (purchase intention).

Thus, we can conclude that the two sub variables of engagement -perceived interactivity and perceived value- have a significant positive relationship to purchase intention.

The findings also indicate that perceived interactivity is a stronger predictor of purchase intention than perceived value which was supported by Watson et al. (2018) argued that interactivity is a key feature of $A R$ applications. This could be explained as high levels of interactivity in a virtual world, supplies the users' mind with a sense of control and autonomy. (Kim et al., 2014).

\section{H3: User experience has a significant effect on purchase intention}

H3a: hedonic dimension has a significant effect on purchase intention

$\mathrm{H} 3 \mathrm{~b}$ : cognitive dimension has a significant effect on purchase intention

Table 10: The Stepwise Multiple Regression results

\begin{tabular}{l|c|c|c}
\hline \multicolumn{1}{c|}{ Predictors } & $\begin{array}{c}\text { Beta } \\
\text { value }\end{array}$ & t value & Significant \\
\hline $\begin{array}{l}\text { Cognitive } \\
\text { dimension }\end{array}$ & .621 & 12.403 & 0.000 \\
\hline $\begin{array}{l}\text { Hedonic } \\
\text { dimension }\end{array}$ & .188 & 3.782 & 0.000 \\
\hline F Value=459.804 & & \\
\hline R Square $=.621$
\end{tabular}

The Beta value of the cognitive dimension of experience was .0.621 and value (12.403) and its significant at (0.00). In addition, the Beta value of the hedonic dimension of experience was .188 and $t$ value (3.782) and its significant at (0.00). The $\mathrm{F}$ value was 459.804and significant at (0.00), consequently the $\mathrm{r}$ square value was .621meaning that the studied sub variables of experience explain about $62.1 \%$ for the variance of dependent variable (purchase intention). This means that the two sub variables of experience- cognitive and hedonic dimensions- have a significant positive effect on purchase intention. Thus, H3 is accepted (see Table $10)$.

The findings of this research were supported by the study of Cehovin, F. and Ruban, B. (2017) and Blázquez, (2014) who stated that studies on AR users' experience show that both hedonic and cognitive drivers affect the shopping experience.

However, the findings confirm that the cognitive dimension explains more for the variance of purchase intention, which contradicts with those of Watson et al. (2018) who argued that AR provides a more hedonic than cognitive shopping experience. This could be traced back to the fact that Egyptian customers are more rational and seek efficiency when shopping especially when buying furniture.

\subsection{Qualitative Data Analysis}

The Socio -demographics questions were analyzed to gain deeper understanding of the respondent's familiarity, usage rate and perception of AR Technologies especially the IKEA App.

It was concluded that a majority of $54.8 \%$ were not familiar with AR technology. The majority of the respondents who previously tried AR rated their 
usage frequency as occasionally with $38.6 \%$, rarely with $30.7 \%$, frequently with $23.2 \%$, always with $4.3 \%$, and finally never with $3.1 \%$.

The analysis revealed that $94 \%$ showed interest in trying AR. In addition, a majority of $70.1 \%$ of IKEA customers never used the IKEA place and only $29.9 \%$ used it before.

When the respondents were asked about their usage rate of the IKEA place App, a majority of 32.7\% have tried the App only once, $21.4 \%$ tried it 1-4 weeks, $17.3 \%$ responded "hard to say", $16.1 \%$ used it 1-3 months and $12.5 \%$ used it more than 3 months. Moreover, a majority of $85.9 \%$ did not use any other AR apps in shopping and a majority of $97.5 \%$ agreed that AR will help them make better purchase decisions. In addition, $98.8 \%$ felt secure about using such technology. Finally, $46.6 \%$ responded definitely on consider using AR apps in the future, $31 \%$ answered most likely, $20.1 \%$ responded probably, $1.4 \%$ responded unlikely and 1.1 responded not at all. Consequently, the researcher came to the conclusion that Egyptian customers were mostly unfamiliar with AR however, they showed high interest in trying it in their shopping as they perceived it as secure and helpful in their decisionmaking process.

the survey also included some multiple response questions where customers were allowed to choose more than one response for the same question as well as writing their own opinion if they need to further elaborate their perception. The respondents were asked about the reasons that would encourage them to use AR as well as their perception of the advantages and disadvantages of such technology.

Starting with the reasons that would encourage respondents to use AR, the majority of the respondents with $30.9 \%$ agreed that they would use AR to try something new while $24.3 \%$ would be encouraged to use it to fulfil an actual need. $19.5 \%$ would use it just out of curiosity about AR, 13\% would use it because a friend suggested it and 7.7\% would use it because a store or brand suggested it. Only a minority of $4.6 \%$ said they would use it because they saw an advertisement about it.

Moving to the advantaged of AR in shopping $31.2 \%$ responded that the main advantage is the "try before buy" feature while $22.3 \%$ found that customization and personalization is one of the main advantages of AR. In addition, 18.6 voted for ease of selection and comparison while $12.5 \%$ chose information availability and accessibility and 8.6 voted of quick retrieval of content. A minority of $6.7 \%$ found that AR'S advantage is its usefulness.

Moreover, $33.4 \%$ agreed that the main disadvantage of AR the technical problems such as camera, internet connection etc. In addition, $17.9 \%$ found the disadvantage of $\mathrm{AR}$ is the irrelevant information and

\section{ISSN 2455-6378}

content. 16.4\% voted for unreliable application and poor support, $12.6 \%$ argued that the main disadvantage is lack of product and choice while $10.4 \%$ think it's the limited functions and features. Finally, a minority of $9.2 \%$ argued that the disadvantage lies in the user interface complexity.

\section{Conclusions}

This research contributes to the body of knowledge relating to the use of $\mathrm{AR}$ in the retail sector by developing a new model of how using AR technology that includes high levels of engagement affects a user's virtual experience and in turn all together affect the user's purchase intention. In today's world, where consumers make their purchase decisions rapidly and switch between different brands more frequently, using AR is highly valued and recommended.

Overall, the researcher found a significant influence of AR on both the hedonic and the cognitive dimension of the consumer experience during their decision-making process. However, the company applying AR technology needs to put special attention on the type of customers the company is dealing with to be able to identify the level of hedonic and cognitive value that should be included. Further, perceived interactivity was found to have a higher impact on the user's experience compared to perceived value which indicates that customer's place higher value on AR apps that allow them to interact with the product and modify its content.

\section{Reference}

[1] Bilgihan, A., Kandampully, J. and Zhang, T., Towards A Unified User Experience in Online Shopping Environment. International Journal of Quality and Service Sciences, 8(1), pp.102-119, (2016).

[2] Blázquez, M., Fashion Shopping in Multichannel Retail: The Role of Technology in Enhancing the Customer Experience. International. Journal of Electronic Commerce, 18(4), pp.97-116, (2014).

[3] Bonetti, F, Wamaby, G \& Quinn, L, Augmented Reality and Virtual Reality in Physical and Online Retailing: A Review, Synthesis and Research Agenda. International Augmented Reality and Virtual Reality Conference. Manchester Metropolitan University. https://doi.org/10.1007/978-3-31964027-3_9, (2017).

[4] Bonsón Ponte, E. et al., Influence of Trust and Perceived Value on The Intention to Purchase Travel Online: Integrating the Effects of Assurance on Trust Antecedents. Journal of Tourism Management 47, pp. 286-302. doi: 10.1016/j.tourman.2014.10.009, (2015). 
[5] Caboni, F. and Hagberg, J., Augmented Reality in Retailing: A Review of Features, Applications and value. International Journal of Retail \& Distribution Management, 47(11), pp.1125-1140 (2019).

[6] Cehovin, F. and Ruban, B., The Impact of Augmented Reality Applications on Consumer Search and Evaluation Behavior. CBS Copenhagen business school, Denmark, (2017)

[7] Chi H., and Ren Yeh H., and Ching Tsai Y., The Influences of Perceived Value on Consumer Purchase Intention: The Moderating Effect of Advertising Endorser. Journal of International Management Studies (2011).

[8] Childers, T., Carr, C., Peck, J. and Carson, S., Hedonic and Utilitarian Motivations for Online Retail Shopping Behavior. Journal of Retailing, 77(4), pp.511-535, (2001).

[9] Dacko, S., Enabling Smart Retail Settings Via Mobile Augmented Reality Shopping Apps. Journal of Technological Forecasting and Social Change 124, pp. 243-256. doi: 10.1016/j.techfore.2016.09.032, (2016).

[10]Dieck, T. and Jung, T., Value of augmented reality at cultural heritage sites: A stakeholder approach. Journal of Destination Marketing \&

[11]Domina, T., Lee, S. and MacGillivray, M., Understanding factors affecting consumer intention to shop in a virtual world. Journal of Retailing and Consumer Services, 19(6), pp.613620, (2012)

[12]Fornell, C. a., Discriminant Validity Assessment: Use of Fornell \&Larcker Criterion versus HTMT Criterion. Journal of Physics (2017).

[13] Hilken, T., de Ruyter, K., Chylinski, M., Mahr, D. and Keeling, D., Augmenting the Eye of The Beholder: Exploring the Strategic Potential of Augmented Reality to Enhance Online Service Experiences. Journal of the Academy of Marketing Science, 45(6), pp.884-905, (2017).

[14]Huang, T. and Hsu Liu, F., Formation of Augmented-Reality Interactive Technology's Persuasive Effects from the Perspective of Experiential value. Journal of Internet Research, 24(1), pp.82-109, (2014).

[15]Huang, T. and Liao, S., A Model of Acceptance of Augmented-reality Interactive Technology: The Moderating Role of Cognitive Innovativeness. Journal of Electronic Commerce Research, 15(2), pp.269-295, (2014).

[16] Kim, K., Hwang, J., Zo, H. and Lee, H., Understanding Users' Continuance Intention Toward Smartphone Augmented Reality Applications. Journal of Information Development, 32(2), pp.161-174, (2014).

[17]Krejcie, R. and Morgan, D., Determining Sample Size for research activities, Journal of
ISSN 2455-6378

educational and psychological measurements 30 (3), (1970).

[18]Mollen, A. and Wilson, H., Engagement, Telepresence and Interactivity in Online Consumer Experience: Reconciling Scholastic and Managerial Perspectives. Journal of Business Research, 63(9-10), pp.919-925, (2010).

[19] O'Leary-Kelly S., \& Robert J. Vokurka, The Empirical Assessment of Construct Validity. Journal of Operations Management, 16 (4), pp. 387-405, (1998).

[20] Olsson, T., Lagerstam, E., Kärkkäinen, T. and Väänänen-Vainio-Mattila，K. (2011). Expected user Experience of Mobile Augmented Reality Services: A User Study in The Context of Shopping Centers. Journal of Personal and Ubiquitous Computing, 17(2), pp.287-304.

[21] Pantano, E., Rese, A. and Baier, D., Enhancing the Online Decision-making Process by Using Augmented Reality: A Two Country Comparison of Youth Markets. Journal of Retailing and Consumer Services, 38, pp.81-95, (2017).

[22] Papagiannidis, S., Pantano, E., See-To, E., Dennis, C. and Bourlakis, M., To Immerse or Not? Experimenting with Two Virtual Retail Environments. Information Journal of Technology \& People, 30(1), pp.163-188, ((2017).

[23] Papagiannidis, S., Pantano, E., See-To, E.W. and Bourlakis, M., Modelling the Determinants of a Simulated Experience in a Virtual Retail Store and Users' Product Purchasing Intentions. Journal of Marketing Management, 29(13-14), pp.1462-1492, (2013)

[24] Perannagari, K. and Chakrabarti, S., Factors Influencing Acceptance of AR in Retail: Insights from Thematic Analysis. International Journal of Retail \& Distribution Management, 48(1), pp.18-34, (2019).

[25] Poushneh, A. and Vasquez-Parraga, A., Discernible Impact of AR on Retail Customer's Experience, Satisfaction and Purchase Intention. Journal of Retailing and Consumer Services, 34, pp.229-234, (2017).

[26] Rese, A., Baier, D., Geyer-Schulz, A. and Schreiber, S., How AR Apps are Accepted by Consumers: A Comparative Analysis Using Scales and Opinions. Journal of Technological Forecasting and Social Change, 124, pp.306319, (2017).

[27] Hair J., Marko Sarstedt, Christian M. Ringle, \& Jeannette A. Mena. An Assessment of The Use of Partial Least Squares Structural Equation Modeling in arketing research. Journal of the Academy of Marketing Science, 40 (3), p. 414433, (2012). 
International Journal of Advanced Scientific Research and Management, Volume 5 Issue 11, Nov 2020

[28] Saunders, M. et al., Research methods for business students. $7^{\text {th }}$ ed, Pearson Education Limited, Edinburg Gate, (2015)

[29] Scholz, J. and Smith, A., Augmented reality: Designing Immersive Experiences that Maximize Consumer Engagement. Journal of Business Horizons 59(2), pp. 149-161. doi: 10.1016/j.bushor.2015.10.003, (2016)

[30] Tabusca A., Augmented reality - need, opportunity or fashion. Journal of Information

\section{ISSN 2455-6378}

Systems \& Operations Management 8(2), 1-11 (2014).

[31] Management, $\quad 6(2), \quad$ pp. 110-117. doi: 10.1016/j.jdmm.2017.03.002, (2017)

[32] Watson, A., Alexander, B. and Salavati, L, The Impact of Experiential AR Applications on Fashion Purchase Intention. International Journal of Retail \& Distribution Management, 48 (5) PP. 433-451 (2018). 